\title{
Effect of vapour pressure deficit on gas exchange of field-grown cotton
}

\author{
BROUGHTON Katrina J. ${ }^{1,2,3^{*}}$ (D, PAYTON Paxton ${ }^{4}$, TAN Daniel K. Y. ${ }^{2}$, TISSUE David T. ${ }^{3}$ and BANGE Michael P. ${ }^{1,2,3}$
}

\begin{abstract}
Background: Plants respond to changes in vapour pressure deficit (VPD) between the leaf and the atmosphere through changes in stomatal response, which can consequently affect transpiration, photosynthesis, and leaf-level water use efficiencies. With projected warmer air temperatures, changes in rainfall distribution and altered VPD in future climates, it is important to understand the potential effect of VPD on leaf-level physiology of field-grown crops. The aim of this study was to assess the impact of altered VPD on leaf-level physiology of field-grown cotton to improve the current understanding of the plant-by-environment interaction, thereby contributing to validation and improvement of physiological and yield response models. Different VPD environments in the field were generated by planting cotton on three dates within the sowing window (early-season (S1) =5th October 2011; mid-season (S2) =9th November 2011; and late-season (S3) =30th November 2011). VPD was also modified by altering crop irrigations.
\end{abstract}

Results: VPD $\mathrm{L}_{\mathrm{L}}$ accounted for the largest proportion of the explained variation in both stomatal conductance (32\% 39\%) and photosynthetic (16\% 29\%) responses of cotton. Generally, smaller percentages of variation were attributed to other main factors such as the individual plant (Plant), and accumulated temperature stress hours (ASH; a measure of plant water status over time) and interactive factors, including leaf vapour pressure deficit $\left(V P D_{L}\right) \times$ Plant and Plant $\times$ ASH; however, a proportion of variation was unexplained. In addition, the $A_{\text {sat }} / E$ (instantaneous transpiration efficiency, ITE) model developed based on cotton grown in the glasshouse was applied to cotton grown in the field. We found that the modelled $A_{\text {sat }} / E$ and field-measured $A_{\text {sat }} / E$ were very similar, suggesting that the mechanistic basis for ITE was similar in both environments.

Conclusions: This study highlights the importance of accounting for VPD in climate change research, given that stomata are highly responsive to changes in VPD. This experiment provides a basis for physiology and production models, particularly in terms of cotton response to projected climatic environments.

Keywords: Climate change, Gossypium hirsutum, Physiology, VPD

\section{Introduction}

With global warming, there are likely to be increases in both daytime and night-time temperatures, with nighttime temperatures warming more quickly than daytime temperatures (Cox et al. 2020; IPCC 2014, 2021). If the diurnal temperature range remains constant, global

*Correspondence: katie.broughton@csiro.au

${ }^{1}$ CSIRO Agriculture and Food, Locked Bag 59, Narrabri, NSW, Australia

Full list of author information is available at the end of the article warming will lead to an increase in vapour pressure deficit (VPD) because the saturated vapour pressure curve is steeper at higher temperatures than that at lower temperatures (Kirschbaum 2004). However, there is likely to be a shift in climatic zones, with projections for wetter conditions throughout India and northern tropical Africa and drier conditions over nearly all other land regions (Sherwood and Fu 2014). With potentially warmer temperatures, changes in rainfall distribution and altered VPD in future climates, it is important to understand the original author(s) and the source, provide a link to the Creative Commons licence, and indicate if changes were made. The images or other third party material in this article are included in the article's Creative Commons licence, unless indicated otherwise in a credit line to the material. If material is not included in the article's Creative Commons licence and your intended use is not permitted by statutory regulation or exceeds the permitted use, you will need to obtain permission directly from the copyright holder. To view a copy of this licence, visit http://creativecommons.org/licenses/by/4.0/. 
potential impact of VPD on leaf-level physiology of fieldgrown crops, which will lead to a broader understanding of crop responses to projected future climates.

In cotton growing regions, atmospheric VPD is generally lower in the early growing season, when air temperatures are cooler; and higher in the later growing season, when air temperatures are warmer and relative humidity is lower. In addition to seasonal variation, VPD often changes throughout the day with rising temperature generating higher VPD (Pettigrew et al. 1990). Plant water availability during critical growth periods may affect physiological processes and productivity. The average annual rainfall across Australian cotton production areas ranges from 350 to $700 \mathrm{~mm}$ (Tennakoon and Milroy 2003). Most cotton in Australian is irrigated, so the planting area depends on the availability of irrigation water, which is essential to achieve high yield in Eastern Australia because in-season precipitation is frequently insufficient to meet the water demand of crops (Tennakoon and Hulugalle 2006). Greater transpiration rates at high VPD will lead to increased water consumption by plants during the season, and thus it is necessary to understand the impacts of VPD on the physiology of field-grown cotton, in conjunction with developing genotypes that use less water in high VPD environments (Devi and Reddy 2018; Shekoofa et al. 2021).

Plants respond to changes in VPD between the leaf and the atmosphere through changes in stomatal response (Devi and Reddy 2018; Grantz 1990; Shekoofa et al. 2021). Increasing VPD has been shown to linearly increase transpiration $(E)$ at the leaf-level (Rawson et al. 1977; Yong et al. 1997), despite a decrease in stomatal conductance $\left(g_{s}\right)$, which has been observed in leaves of glasshouse grown cotton (Duursma et al. 2013; Slatyer and Bierhuizen 1964). By mitigating high $E$ that would otherwise be caused by increasing VPD, stomatal closure avoids the corresponding decline in plant water potential (Oren et al. 1999). Studies have also shown that $g_{\mathrm{s}}$ decreases with increasing VPD, although the precise mechanism is not clear (Conaty et al. 2014; Yong et al. 1997); in most cases, $g_{s}$ decreases exponentially with increasing VPD, although there may be differences in physiological response between cotton cultivars (Devi and Reddy 2018).

There is also evidence that increasing VPD can cause inhibition of photosynthesis unrelated to stomatal closure (Morison and Gifford 1983; Pettigrew et al. 1990). However, Duursma et al. (2013) found that in cotton, photosynthesis was relatively insensitive to VPD as it decreased 13\% (on average) from the maximum photosynthetic rate over a wide range of VPD $(1 \mathrm{kPa} \sim 4 \mathrm{kPa})$. Rawson et al. (1977) compared the VPD response of a number of $\mathrm{C}_{3}$ species, including wheat, soybean, sunflower and sorghum, to step changes in VPD (range $0.8 \sim \mathrm{kPa} 2.7 \mathrm{kPa}$ ) and found little or no response to VPD in these species, which were grown under the conditions of sufficient light and water, and maintained at a mean temperature of $26^{\circ} \mathrm{C}$. Franks and Farquhar (1999) found that wheat and broad bean were relatively insensitive to changes in VPD, suggesting that crop plants may have indirectly been selected for high $g_{\mathrm{s}}$ in the interest of maximising productivity. However, it should be noted that high $g_{\mathrm{s}}$ may contribute to very high rates of transpiration under natural conditions (Franks and Farquhar 1999).

Using the model of Medlyn et al. (2011), Duursma et al. (2013) showed that cotton was sensitive to VPD when grown in a glasshouse under variable $\left[\mathrm{CO}_{2}\right]$ and temperature conditions; however, these models have not been tested on field-grown cotton. Although there have been some studies testing the response of cotton to varied VPD in either glasshouses or growth chambers (Devi and Reddy 2018), VPD experiments on field-grown Australian cotton are limited. The objective of this research was to assess the impact of altered VPD on leaf-level physiology of cotton grown in Australian field conditions and examine the environmental variables that influence changes in stomatal and photosynthetic responses. In this study, we tested the hypotheses that (1) increased VPD will reduce stomatal conductance in the field; (2) variation in stomatal conductance and photosynthetic rates can be explained by changes in growth conditions and consequently variables that describe the environmental factors; and (3) the instantaneous transpiration efficiency (ITE; equivalent to $A_{\text {sat }} / E$ ) model developed using cotton grown in glasshouse conditions (Duursma et al. 2013) can be used to estimate $A_{\text {sat }} / E$ of field-grown cotton.

\section{Materials and methods}

\section{Experimental design and plot management}

Cotton (Gossypium hirsutum, cv. 71BRF [Bollgard $\mathrm{II}^{\circledR}$ Roundup Ready Flex ${ }^{\circledR}$ ], CSIRO Australia) was grown at the Australian Cotton Research Institute (ACRI), Narrabri, NSW during the 2011/12 growing season. Cotton was planted at a row spacing of $1 \mathrm{~m}$ with a sowing density of 14 plant. $\mathrm{m}^{-2}$ on three dates within the sowing window: early-season $(S 1)=5$ th October 2011; mid-season $(\mathrm{S} 2)=9$ th November 2011; late-season $(\mathrm{S} 3)=30$ th November 2011 . The three sowing times exposed developing cotton to different minimum and maximum temperatures and relative humidity, consequently resulting in different atmospheric VPD within the same cotton developmental state, and then the physiological responses to VPD was measured. Experiments were managed according to current Australian practices, except for imposed irrigation treatments as outlined. 
Daily weather conditions, including minimum and maximum air temperatures and rainfall events were obtained from the Myall Vale weather station (Fig. 1). The authors acknowledge that data for this study was from 2011. Weather conditions are usually highly variable between years, however, a separate study of climate change across Australian cotton regions shows that there has been no significant change in minimum temperature, temperatures above $40{ }^{\circ} \mathrm{C}$, or rainfall distribution in Narrabri from 1997 to 2018 (Broughton et al., in press). Therefore, we are comfortable using data from 2011 for this study, which focuses more on the physiological response of cotton to differing environmental conditions rather than specific climates.

Soil water availability was manipulated using three irrigation treatments: (a) fully watered-non-stressed (NS); (b) limited water-early stress (ES); and (c) limited water-late stress (LS). Similar to the sowing time, the purpose of the irrigation treatments was to generate different VPD environments within each cotton developmental stage rather than assessing the effect of water stress on cotton physiology. The first irrigation event was skipped for the ES. One irrigation event was skipped during the early boll-fill stage for the LS. Plastic was used to cover the ground during the water stress treatments to reduce the risk of rainfall prematurely alleviating the stress. However, heavy rainfall and flooding during the season led to the exclusion of measurements in some of the treatments (i.e., the first sowing and late season water stress). Furrow irrigation and rainfall events resulted in lower VPD environments and skipped irrigation treatments resulted in higher VPD environments during periods of measurement.

Each plot consisted of two rows of furrow-irrigated cotton with an additional two-row buffer around (a total of four rows per plot). Plants were irrigated down the centre three rows to minimise the lateral movement of water from the fully irrigated to the water-stressed plots. Each row was $66 \mathrm{~m}$ long, except for the three control irrigation treatments, which were each $22 \mathrm{~m}$ long. The field replication is not orthogonal in design due to logistical difficulties in applying irrigation treatments and laying the plastic, however, the purpose was to generate differences in VPD. Plant response to the variable environment was determined through measuring gas exchange of $2 \sim 3$ different plants per day in each sampling period.

\section{Leaf gas exchange}

Net photosynthesis $\left(A_{\text {sat }}\right)$ and stomatal conductance $\left(g_{\text {s-sat }}\right)$ under saturating light were measured on recently fully expanded leaves using a portable open gas exchange system (LI-6400XT, LI-COR, Lincoln, USA). Leaf gas exchange measurements were taken at saturating light (photosynthetic photon flux density of $\left.2000 \mu \mathrm{mol} \cdot \mathrm{m}^{-2} \cdot \mathrm{s}^{-1}\right), 400 \mu \mathrm{L} \cdot \mathrm{L}^{-1}\left[\mathrm{CO}_{2}\right]$, and block temperature was set to the anticipated mid-day temperature.

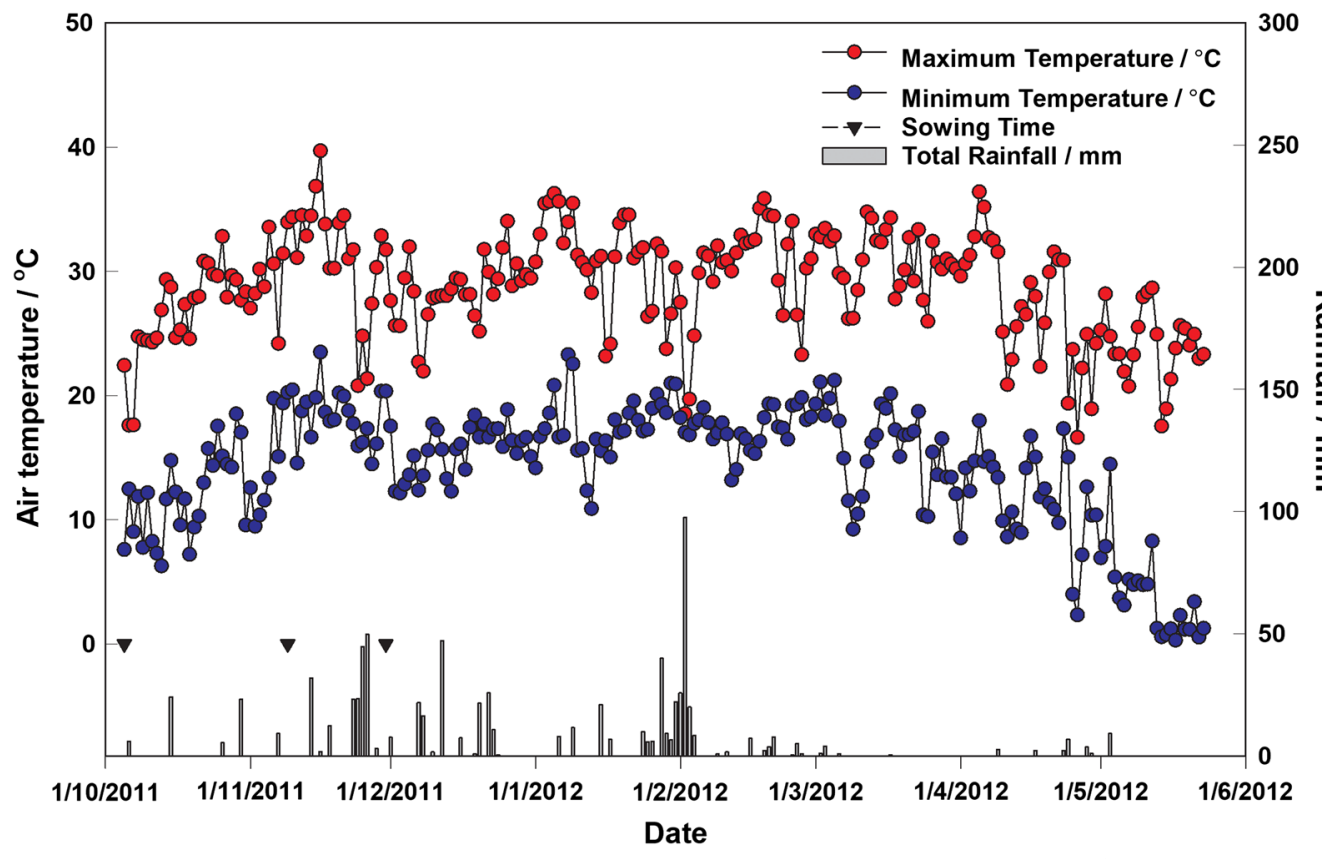

Fig. 1 Daily minimum $\left({ }^{\circ} \mathrm{C}\right.$, blue) and maximum $\left({ }^{\circ} \mathrm{C}\right.$, red) air temperature and rainfall (mm, grey) at ACRI, Narrabri from 5 th October 2011 to 23 rd May 2012, respectively. Sowing dates (triangles) were 5th October 2011 (S1), 9th November 2011 (S2) and 30th November 2011 (S3) 
VPD response curves were achieved by controlling VPD (temperature $\times$ relative humidity) at the leaf surface within the infrared gas analyzer (IRGA) chamber. Measurements began on full-bypass of air, representing natural ambient humidity conditions in the field; these initial measurements were referred to as the 'field VPD' dataset. Subsequently, water from the incoming air was slowly absorbed using the desiccant Drierite (W. A. Hammond Drierite Co., USA), but block temperature remained the same, thereby increasing leaf vapour pressure deficit $\left(\mathrm{VPD}_{\mathrm{L}}\right)$ by approximately $0.5 \mathrm{kPa}$ for each gas exchange measurement. All gas exchange measurements, including these VPD response curves, were referred to as the 'variable VPD' dataset. The number of measurements captured for each response curve varied because of differences in the range of VPD generated by the IRGA at each time and day.

Measurements were made between the hours of $10 \mathrm{am}$ to $3: 30 \mathrm{pm}$ (Australian Eastern Daylight Time, AEDT), over 3 or 4 consecutive days at different times during the soil water stress treatment. Measurements during the same period of consecutive days were made on the same recently mature leaf (3rd leaf from the top of the plant on the first day of measurement), which had been tagged. Each leaf was allowed approximately $2 \mathrm{~min}$, or until parameters stabilised, to equilibrate before the reading was recorded. Leaf gas exchange measurements of the equivalent control (i.e., non water-stressed treatment) plants were taken on the same day as the water-stressed plants. Two or three plants from each plot were measured per day.

\section{Soil water status}

A neutron probe was used to monitor soil water content at $0.2 \mathrm{~m}$ intervals to a depth of $1.2 \mathrm{~m}$. These measurements were taken every 10 days throughout the season, and each week during water stress treatments. Volumetric soil water content (VSWC, \%) was calculated using a formula, which was calibrated for soils in an adjacent field, with the same soil classification at ACRI (Ward et al. 1999). $\operatorname{VSWC}(\%)=0.0006 \mathrm{x}+24.225$; where $\mathrm{x}$ is the count measurement at each depth (Warren Conaty, pers comm.). VSWC(\%) was averaged across all depths (i.e., $0 \sim 120 \mathrm{~cm}$ ).

\section{Canopy temperature}

Wireless, battery-operated SmartCrop infrared thermometers (Smartfield Inc., Lubbock, TX, USA) were used to monitor canopy temperature in each plot. Sensors were periodically repositioned to maintain them at $20 \sim 30 \mathrm{~cm}$ above the canopy pointing south at an angle of $45^{\circ}$ to the horizontal during the measurement. Where possible, two sensors were placed towards the centre of each plot; however, some plots only had one sensor due to a limited number of sensors. Stress hours were recorded by the SmartCrop sensors as hours that the canopy temperature was above $28{ }^{\circ} \mathrm{C}$, which is considered the optimal thermal temperature for cotton (Conaty 2011), while regardless of actual canopy temperature. These data were used to calculate accumulated temperature stress hours (ASH) between irrigation events, similar to the calculation of heat units by Mahan et al. (2014).

\section{Statistical analysis \\ Testing treatment effects}

Summary statistics were used to explore the variation generated by the sowing dates and water treatment effects across the variable VPD dataset.

\section{Testing environmental effects}

Generalised linear models were used to link the responses of field-grown cotton to the treatment effects with the overall responses of the plants to the biological and environmental responses. To test model effects, data were analysed using Genstat version 16 (VSN International, Hemel Hempstead, UK) by forward stepwise regression. Variables were sequentially added to the model using a significance level of 0.05 to determine if the variable remained in the model. This method was used both for the field VPD dataset and the variable VPD dataset for both stomatal conductance and photosynthesis. A number of variables were tested, but the best maximal model for both stomatal conductance and photosynthesis was found to be: $\mathrm{VPD}_{\mathrm{L}} \times$ Plant $\times \mathrm{ASH}$, where: $\mathrm{VPD}_{\mathrm{L}}$ is leaf-level vapour pressure deficit, Plant is the individual plant, and ASH is accumulated temperature stress hours. Stomatal conductance data were transformed logarithmically, which improved $R^{2}$ over a linear regression (from 0.387 to 0.428 ). Note that while the individual plant was a random effect rather than an environmental variable, variation attributed to the plant needed to be taken into account as part of the regression analysis.

\section{Testing the Asat/E (ITE) model}

Duursma et al. (2013) showed that for cotton grown in a controlled environment glasshouse (in ambient and elevated $\mathrm{CO}_{2}$ and temperature treatments), the following equation gave satisfactory fits to measured ITE when VPD was varied independently of temperature and other environmental drivers:

$$
I T E=\frac{A}{E}=\frac{C_{a} P_{a}}{g_{1} D s^{k}+D s}
$$

where ITE is the ratio of photosynthesis to transpiration $\left(\mu \mathrm{mol} \cdot \mathrm{mmol}^{-1}\right), C_{\mathrm{a}}$ is atmospheric $\left[\mathrm{CO}_{2}\right](\%), P_{\mathrm{a}}$ is 

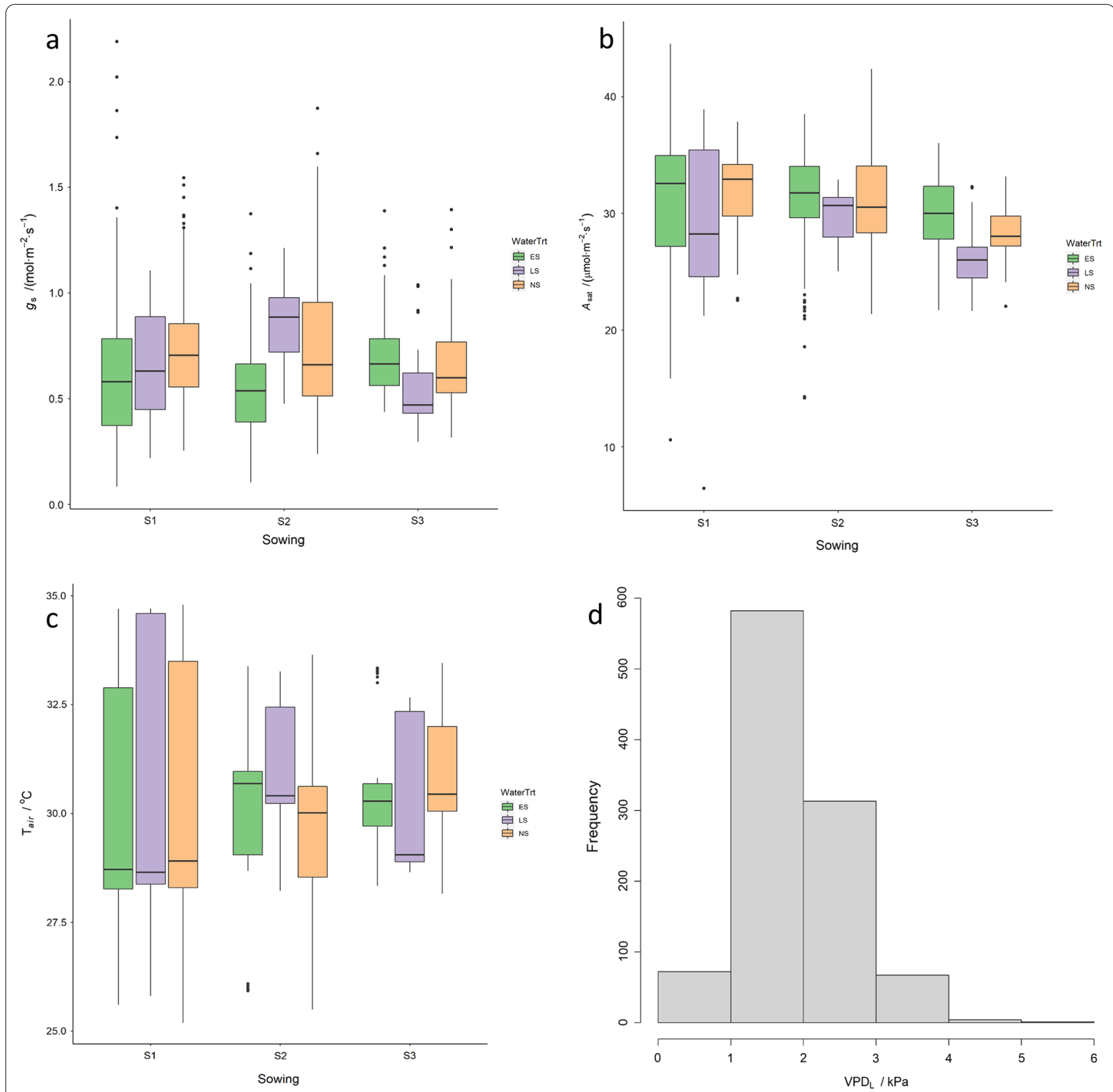

Fig. 2 Variation in a stomatal conductance $\left(g_{s}\right)$, b photosynthesis $\left(A_{\text {sat }}\right)$, and $\mathbf{c}$ air temperature $\left(T_{\text {air }}\right)$ for sowing time and water treatments; and $\mathbf{d}$ the frequency of gas exchange measurements in different VPD environments. Sowing dates were 5th October 2011 (S1), 9 th November 2011 (S2) and 30th November 2011 (S3), respectively. Water treatments were early limited water (ES, green), late limited water (LS, purple) and non-stressed (NS, orange), respectively

the atmospheric pressure $(\mathrm{kPa}), g_{1}$ is the 'slope parameter' which is related to the marginal cost of water (see Medlyn et al. 2011 for details), $D_{\mathrm{s}}$ is the leaf-to-air vapour pressure deficit $(\mathrm{kPa})$, and $k$ is an empirical parameter. Based on the assumption that stomata respond optimally to changes in VPD, $k$ would equal to 0.5 .
To test whether this model, and the parameters estimated by Duursma et al. (2013) are suitable to estimate $A_{\text {sat }} / E$ in field conditions, Eq. (1) was fitted to a "wellwatered" subset of the VPD measurements of field grown cotton using $\mathrm{R}$ (version 3.1.0). $\mathrm{R}$ was the preferred software for this analysis because of easier application of the model. The "well-watered" subset based on VPD data 
Table 1 Percentage variation in stomatal conductance $\left(g_{\text {s-sat }}\right)$ and photosynthesis $\left(A_{\text {sat }}\right)$, explained by the addition of each of the variables assessed for the field VPD and Variable VPD datasets

\begin{tabular}{|c|c|c|c|c|}
\hline & \multicolumn{2}{|c|}{$\begin{array}{l}\text { Field VPD, variation } \\
\text { account } / \%\end{array}$} & \multicolumn{2}{|c|}{$\begin{array}{l}\text { Variable VPD, } \\
\text { variation } \\
\text { account } / \%\end{array}$} \\
\hline & $g_{s-s a t}$ & $A_{\text {sat }}$ & $g_{s-s a t}$ & $A_{\text {sat }}$ \\
\hline$V P D_{L}$ & 39.5 & 28.9 & 32.3 & 16.8 \\
\hline Plant & 4.8 & 0 & 4.3 & 0 \\
\hline ASH & 0 & 17.1 & 1.6 & 6.7 \\
\hline $\mathrm{VPD}_{\mathrm{L}} \times$ Plant & 0 & 0 & 2.5 & 2.9 \\
\hline $\mathrm{VPD}_{\mathrm{L}} \times \mathrm{ASH}$ & 0 & 0 & 0 & 0 \\
\hline Plant $\times$ ASH & 0 & 0 & 3.1 & 0 \\
\hline $\mathrm{VPD}_{\mathrm{L}} \times$ plant $\times \mathrm{ASH}$ & 0 & 0 & 0 & 0 \\
\hline Total variation & 44.3 & 46.0 & 43.8 & 26.4 \\
\hline
\end{tabular}

VPDL refers to vapour pressure deficit of the leaf, plant refers to the individual plant measured, and ASH refers to accumulated stress hours

within the first five days of gas exchange measurements for each treatment was used because it is known that the model is not appropriate for water-stressed conditions (Remko Duursma, pers. comm). Predicted (modelled) $A_{\text {sat }} / E$ was compared with measured $A_{\text {sat }} / E$ using parameters estimated from (a) the fit to field data and (b) glasshouse prediction data. The root mean square error (RMSE) was used to indicate the goodness-of-fit for model predictions of the measured $A_{\text {sat }} / E$ values. The mean absolute difference (MAD) was used as a measure of the difference between modelled estimates and measured values.

\section{Results}

\section{Treatment effects on cotton physiology}

Using the variable VPD data set, $g_{\mathrm{s} \text {-sat }}$ and $A_{\text {sat }}$ declined in response to rising $\mathrm{VPD}_{\mathrm{L}}$. Summary statistics demonstrated that sowing time and water treatments generated variation in VPD and temperature, which enable a broad range of environmental conditions under which gas exchange responses of cotton were measured. During the experimental period, $\mathrm{VPD}_{\mathrm{L}}$ ranged from $0.5 \mathrm{kPa}$ to $5.1 \mathrm{kPa}$ and $\mathrm{T}_{\text {air }}$ ranged from 25 to $35^{\circ} \mathrm{C}$. These environmental conditions resulted in $g_{s \text {-sat }}$ ranging from 0.08 to $2.19 \mathrm{~mol} \cdot \mathrm{m}^{-2} \cdot \mathrm{s}^{-1}$ and $A_{\text {sat }}$ ranging from 6.6 to $44.5 \mu \mathrm{mol} \cdot \mathrm{m}^{-2} \cdot \mathrm{s}^{-1}$. Variation generated across each sowing time and water treatment is shown in Fig. 2.

\section{Comparison of environmental effects on stomatal conductance and photosynthesis of field-grown cotton using generalised linear models}

Generalised linear models used to assess the environmental effects on $g_{\text {s-sat }}$ of the field VPD measurements indicated that $\mathrm{VPD}_{\mathrm{L}}$ accounted for $39.5 \%$ of the variation (Table 1$)$. The addition of the variable Plant $(+4.8 \%)$ accounted for a total of $44.3 \%$ of the variation. Therefore, the best fitting regression analysis for $g_{\text {s-sat }}$ in field VPD conditions was $\mathrm{VPD}_{\mathrm{L}}+$ Plant.

In comparison, the same generalised linear models used to assess the environmental effects on $g_{s-}$ sat of the variable VPD response curves indicated that $\mathrm{VPD}_{\mathrm{L}}$ alone accounted for $32.3 \%$ of the variation (Table 1). The cumulative addition of Plant $(+4.3 \%), \quad \mathrm{ASH}(+1.6 \%), \quad \mathrm{VPD}_{\mathrm{L}} \times$ Plant $(+2.5 \%)$, Plant $\times$ ASH $(+3.1 \%)$ increased accountable variation to a total of $43.8 \%$. Therefore, the best fitting regression analysis for $g_{\text {s-sat }}$ in the variable VPD dataset was $\mathrm{VPD}_{\mathrm{L}}+$ Plant $+\mathrm{ASH}+\mathrm{VPD}_{\mathrm{L}} \times$ Plant + Plant $\times \mathrm{ASH}$.

Generalised linear models used to assess the environmental effects on photosynthesis of field VPD measurements indicated that $\mathrm{VPD}_{\mathrm{L}}$ accounted for $28.9 \%$ of the variation (Table 1). The addition of ASH $(+17.1 \%)$ improved the model by accounting for a total of $46.0 \%$ of the variation. Therefore, the best fitting regression analysis for photosynthesis at field VPD was $\mathrm{VPD}_{\mathrm{L}}+\mathrm{ASH}$.

In comparison, the same generalised linear models were used to assess the environmental effects on photosynthesis of the variable VPD dataset. $\mathrm{VPD}_{\mathrm{L}}$ accounted for $16.8 \%$ of the variation, and the cumulative addition of $\mathrm{ASH}(+6.7 \%)$, and $\mathrm{VPD}_{\mathrm{L}} \times$ Plant $(+2.9 \%)$ increased accountable variation to a total of 26.4\% (Table 1). Therefore, the best fitting regression for the photosynthesis with the variable VPD dataset was $\mathrm{VPD}_{\mathrm{L}}+\mathrm{ASH}+\mathrm{VPD}_{\mathrm{L}} \times$ Plant.

\section{Estimating ITE $\left(A_{\text {sat }} / E\right)$ for field conditions using the Duursma et al. (2013) model}

$A_{\text {sat }} / E$ showed a strong response to VPD in the field (Fig. 3) and was very similar to the glasshouse. The comparison of modelled and measured $A_{\text {sat }} / E$ using estimated $g_{1}$ and $k$ parameters is shown in Fig. 4. Estimated parameter values of field-grown cotton were $g_{1}=4.35$ (95\% confidence interval $(\mathrm{CI}): 4.24 \sim 4.47)$ and $k=0.59$ (95\% CI: $0.53 \sim 0.64$ ). In addition, for the comparison of modelled and measured $A_{\text {sat }} / E$, we calculated MAD to be 0.546 for field data, whereas the MAD was calculated to be 0.551 by using the prediction data from glasshouse, which are similar.

\section{Discussion}

Environmental conditions in a field can greatly influence crop physiology and yield (Pettigrew et al. 1990). Therefore, it is important to assess the impact of the environment on physiology of field-grown cotton as warmer temperatures, changes in rainfall distribution, and altered VPD are projected as future climate regimes for 


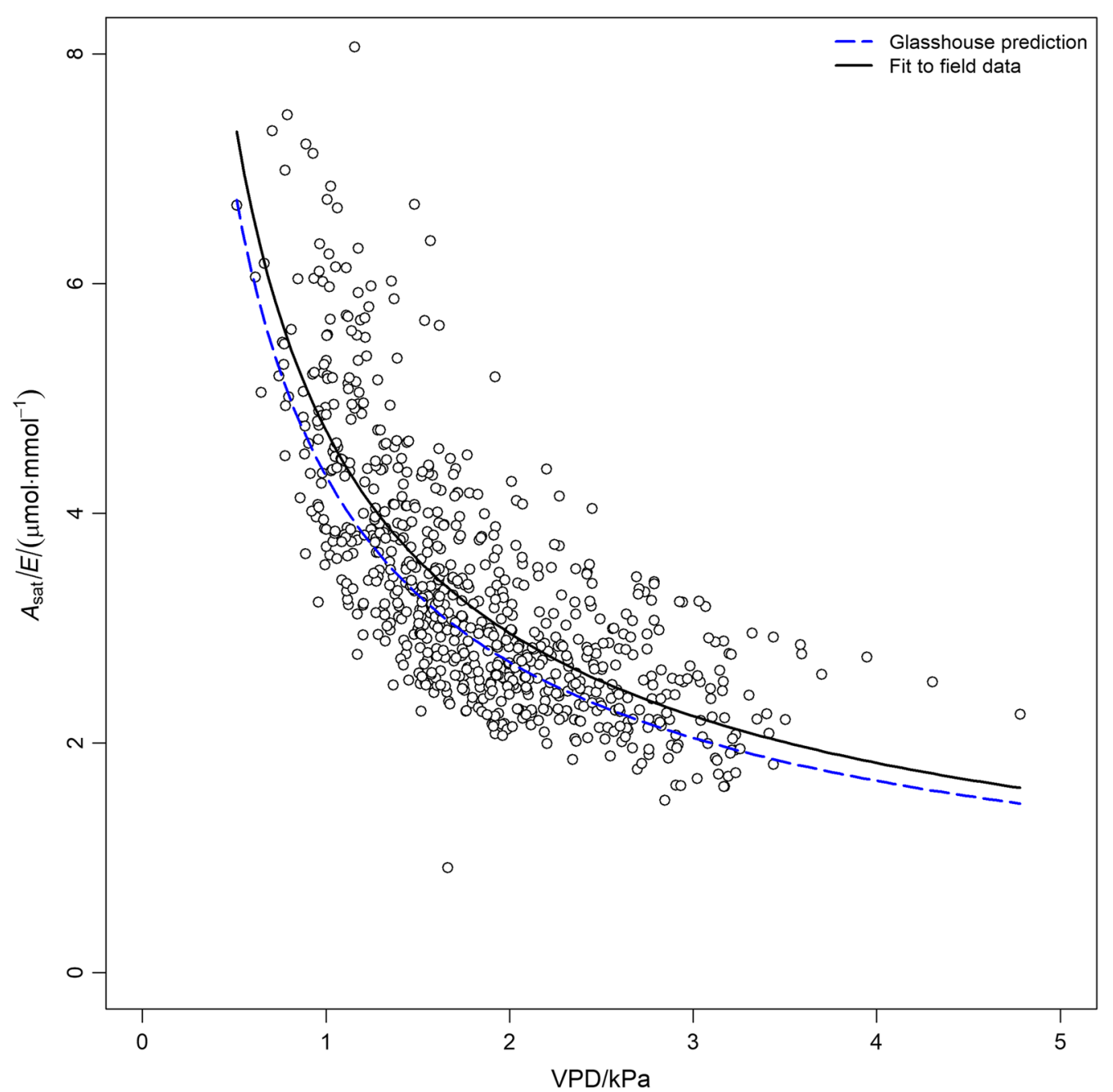

Fig. $3 A_{\text {sat }} / E$ response to VPD of "well-watered" field-grown cotton. Black solid line represents model fit using $g_{1}$ and $k$ estimates from field data. Blue dashed line represents $g_{1}$ and $k$ model prediction based on cotton grown in the glasshouse

Australian cotton regions. In this study, we found that (1) increased $\mathrm{VPD}_{\mathrm{L}}$ reduced stomatal conductance in field-grown cotton; (2) variation in stomatal conductance and photosynthetic rates in the field can be explained by environmental factors, such as VPD and ASH; and (3) the $A_{\text {sat }} / E$ (ITE) model developed using cotton grown in glasshouse conditions can be used to estimate $A_{\text {sat }} / E$ of well-watered field-grown cotton.

In this study, a large proportion of variation in $g_{\text {s-sat }}$ was accounted for by the VPD environment. We found that $\mathrm{VPD}_{\mathrm{L}}$ alone accounted for $32.3 \%$ and $39.5 \%$ of the variation in $g_{s \text {-sat }}$ for the variable VPD and field VPD gas exchange measurements, respectively. Similar to numerous other studies (Duursma et al. 2013; Oren et al. 1999), our data showed a general decline in $g_{\text {s-sat }}$ with rising VPD. Our study highlights that although $\mathrm{VPD}_{\mathrm{L}}$ accounts for a large proportion of the cumulative variation in $g_{s-s a t}$, there were still a number of other variables that influenced variation in stomatal response, including the plant (4.3\%), ASH (1.6\%) and VPD $\times$ Plant $(2.5 \%)$ and Plant $\times$ ASH (3.1\%) interactions in the variable VPD dataset. ASH also contributed a percentage of the variation, highlighting the direct and indirect effects of air temperature on cotton physiology and as a component of VPD. A proportion of variation was also attributed to the individual plant. Although we could account for $c a$. $44 \%$ of variation in $g_{s-\text { sat }}, 56 \%$ of the variation was due to unknown factors, which may include nutrient status of an individual leaf and leaf angle affecting light-interception. Therefore, the success in being able to account for $44 \%$ of the variation in $g_{\text {s-sat }}$ is relatively high given the nature of season-long field measurements.

For photosynthetic responses, $\mathrm{VPD}_{\mathrm{L}}$ accounted for $16.8 \%$ of the variation in the variable VPD dataset, and 

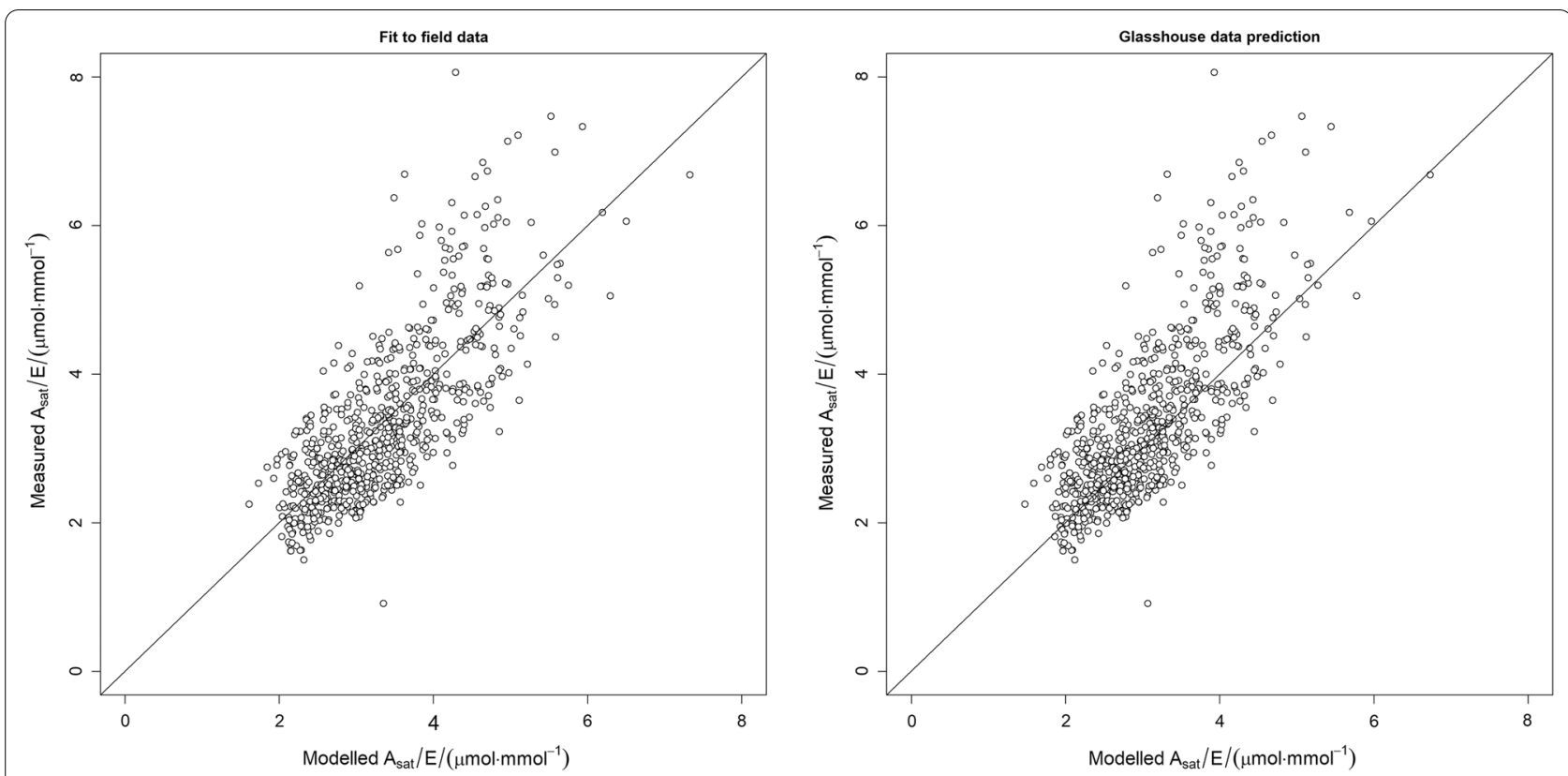

Fig. 4 Comparison of modelled and measured $A_{\text {sat }} / E$ using Eq. (2) where $g_{1}$ and $k$ parameters are from a field data and $\mathbf{b}$ glasshouse data prediction from Duursma et al. (2013). Also shown are the 1:1 lines (black). a RMSE $=0.714$; mean absolute difference $(M A D)=0.546$ and $\mathbf{b}$ RMSE does not apply; MAD $=0.551$

$28.9 \%$ of the variation during field VPD gas exchange measurements. ASH was also an important factor that affected plant photosynthetic response. Adding the variable ASH increased the accountable variation by $6.7 \%$ in the variable VPD dataset and by $17.1 \%$ in the field $V P D$ dataset. The addition of $\mathrm{VPD}_{\mathrm{L}} \times$ Plant was a significant interaction for photosynthetic response in the variable VPD dataset, but not for the field VPD dataset. Other studies reported a lack of response of photosynthesis to altered VPD (Rawson et al. 1977; Yong et al. 1997), although in those experiments temperatures were generally held constant during the study. Similarly, Duursma et al. (2013) found that photosynthesis was relatively insensitive to VPD, however, higher photosynthetic rates of cotton grown at warmer air temperatures resulting in a higher transpiration rate at a given VPD, again highlighting the impact of temperature on photosynthesis. Therefore, studies conducted in highly controlled environments provide a good estimate of the direct effects of VPD, but do not account for the variable temperature conditons observed in the field. Given that ASH accounted for $7-17 \%$ of the variation in photosynthetic rates, this highlights the potential significance of warmer temperatures on photosynthesis of cotton grown in warmer climates in the future, regardless of the small direct impact of VPD on photosynthesis.

The $A_{\text {sat }} / E$ model and the $g_{1}$ and $k$ parameters developed in the glasshouse (Duursma et al. 2013) were successfully used to estimate $A_{\text {sat }} / E$ in the field, which highlights that controlled environment glasshouse studies can be successfully utilised to further our understanding of leaf-level physiological responses of cotton to environmental conditions in the field. Scaling leaf-level responses to the canopy-level and predicting the effect of climate change on crop water use efficiency (Duursma et al. 2013) from glasshouse studies is still difficult across species (Jauregui et al. 2018). For example, although plants were grown in the field, $A_{\text {sat }} / E$ was measured inside the cuvette of the Licor 6400XT, where wind speeds, and thus boundary layer conductance were high (Grantz and Vaughn 1999). Boundary layer conductance can affect leaf temperature, and transpiration rates at a given stomatal conductance, and therefore may not represent gas exchange in field conditions. Therefore, the combination of canopy and leaf-level measurements will be very useful in describing the response of cotton to the environment. Despite these limitations, the success in using the $A_{\text {sat }} / E$ model in both glasshouse and field-grown cotton is promising for the validation of other simulation models. For example, the OZCOT cotton crop simulation model currently does not account for physiological changes in canopy photosynthesis or transpiration in response to $\mathrm{VPD}_{\mathrm{L}}$. Therefore, a better understanding of the physiological responses of crops may improve our predictions of their growth and water use, especially when the simulating the future environments. 


\section{Conclusions}

$\mathrm{VPD}_{\mathrm{L}}$ accounted for a large proportion of the variation in $g_{\text {s-sat }}(32 \% \sim 39 \%)$ and photosynthesis (16\% 29\%) in the field. Approximately $44 \%$ of variation in $g_{\text {s-sat }}$ was successfully accounted for by $\mathrm{VPD}_{\mathrm{L}}$, Plant, $\mathrm{ASH}$ and $\mathrm{VPD}_{\mathrm{L}} \times$ Plant and Plant $\times \mathrm{ASH}$ interactions. Similarly, $26 \% \sim 46 \%$ of variation in photosynthetic rate was accounted for by $\mathrm{VPD}_{\mathrm{L}}, \mathrm{ASH}$, and $\mathrm{VPD}_{\mathrm{L}} \times$ Plant interactions. $A_{\text {sat }} / E$ models and associated parameters that were developed in the glasshouse were successfully used to estimate $A_{\text {sat }} / E$ of field-grown cotton in this study. This could potentially be used to inform crop simulation models, such as the OZCOT cotton model, to account for possible effects of climate change on plant physiology and ultimately on crop production. This study explored physiological responses in a single cotton cultivar, and thus there may be differences in physiological response to $\mathrm{VPD}_{\mathrm{L}}$ between cultivars. In conjunction with information on cotton canopy temperature response (Conaty et al. 2014), and utilising differences in cultivar traits through targeted breeding (Devi and Reddy 2018), a better understanding of VPD impacts on the physiological responses of field-grown cotton may be achieved, which will lead to better mangement of cotton production in future environments.

\section{Abbreviations \\ $A_{\text {sat: }}$ : Photosynthetic rate at saturating light; ASH: Accumulated temperature stress hours; $E$ : Transpiration; $g_{s-\text { sat }}$ : Stomatal conductance at saturating light; ITE: Instantaneous transpiration efficiency; $\mathrm{VPD}_{\mathrm{L}}$ : Vapour pressure deficit of the leaf.}

\section{Acknowledgements}

We would like to thank DUURSMA Remko for his help with data analysis, and the CSIRO cotton agronomy team for their invaluable contributions, especially HODFSON Darin, BECKHOUSE Jo, CATON Jane, SMITH Shanna, COTTEE Nicola, CONATY Warren, CROSS Dominic, JAMISON Stephanie, TANN Marty, and BURLEY Nathan. We also thank JAMALI Hizbullah and CONATY Warren, and anonymous reviewers, for their comments which improved this manuscript.

\section{Authors' contributions}

All authors contributed in shaping the manuscript and providing critical feedback. The authors read and approved the final manuscript.

\section{Funding}

This research was supported by CSIRO, the Cotton Catchment Communities Co-operative Research Centre, the Australian Cotton Research and Development Corporation (CRC 1101), and the Australian Postgraduate Award. The authors declare no conflicts of interest.

\section{Availability of data and materials}

All the related data and files are presented.

\section{Declarations}

Ethics approval and consent to participate

Not applicable.

\section{Consent for publication}

Not applicable.

\section{Competing interests}

The authors declare that they have no competing interests.

\section{Author details}

${ }^{1}$ CSIRO Agriculture and Food, Locked Bag 59, Narrabri, NSW, Australia. ${ }^{2}$ Plant Breeding Institute, Sydney Institute of Agriculture, School of Life and Environmental Sciences, Faculty of Science, University of Sydney, Sydney, NSW, Australia. ${ }^{3}$ Hawkesbury Institute for the Environment, Hawkesbury Campus, Western Sydney University, Penrith, NSW, Australia. ${ }^{4}$ United States Department of Agriculture, Cropping Systems Research Laboratory, Lubbock, TX, USA.

Received: 9 July 2021 Accepted: 17 October 2021

Published online: 15 November 2021

\section{References}

Conaty WC. Temperature-time thresholds for irrigation scheduling in drip and deficit furrow irrigated cotton. Sydney: University of Sydney; 2011 (unpublished doctorial dissertation)

Conaty WC, Mahan JR, Neilsen JE, et al. Vapour pressure deficit aids the interpretation of cotton canopy temperature response to water deficit. Funct Plant Biol. 2014;41:535-46.

Cox DTC, Maclean IMD, Gardner AS, et al. Global variation in diurnal asymmetry in temperature, cloud cover, specific humidity and precipitation and its association with leaf area index. Glob Change Biol. 2020;26:7099-111. https://doi.org/10.1111/gcb.15336.

Devi MJ, Reddy VR. Transpiration response of cotton to vapor pressure deficit and its relationship with stomatal traits. Front Plant Sci. 2018;9:1572. https://doi.org/10.3389/fpls.2018.01572.

Duursma RA, Payton P, Bange MP, et al. Near-optimal response of instantaneous transpiration efficiency to vapour pressure deficit, temperature and $\left[\mathrm{CO}_{2}\right]$ in cotton (Gossypium hirsutum L.). Agric for Meteorol. 2013;168:168-76. https://doi.org/10.1016/j.agrformet.2012.09.005.

Franks PJ, Farquhar GD. A relationship between humidity response, growth form and photosynthetic operating point in $C_{3}$ plants. Plant Cell Environ. 1999;22:1337-49. https://doi.org/10.1046/j.1365-3040.1999. 00494.x.

Grantz DA. Plant-response to atmospheric humidity. Plant Cell Environ. 1990;13:667-79. https://doi.org/10.1111/j.1365-3040.1990.tb01082.x.

Grantz DA, Vaughn DL. Vertical profiles of boundary layer conductance and wind speed in a cotton canopy measured with heated brass surrogate leaves. Agric Meteorol. 1999;97:187-97. https://doi.org/10.1016/s01681923(99)00078-7.

IPCC. Climate change 2014: synthesis report. Contribution of working Groups I, II and III to the fifth assessment report of the intergovernmental panel on climate change. Geneva, Switzerland: IPCC. 2014.

IPCC. Climate change widespread, rapid, and intensifying. Geneva, Switzerland. 2021.

Jauregui I, Rothwell SA, Taylor SH, et al. Whole plant chamber to examine sensitivity of cereal gas exchange to changes in evaporative demand. Plant Methods. 2018;14:97. https://doi.org/10.1186/s13007-018-0357-9.

Kirschbaum MUF. Direct and indirect climate change effects on photosynthesis and transpiration. Plant Biol. 2004;6:242-53. https://doi.org/10. 1055/s-2004-820883.

Mahan J, Young A, Payton P, et al. Effect of differential irrigation on accumulation of canopy temperature-based heat units in cotton. J Cotton Sci. 2014;18:129-36.

Medlyn BE, Duursma RA, Eamus D, et al. Reconciling the optimal and empirical approaches to modelling stomatal conductance. Glob Change Biol. 2011;17:2134-44. https://doi.org/10.1111/j.1365-2486.2010.02375.x.

Morison JIL, Gifford RM. Stomatal sensitivity to carbon-dioxide and humidity-a comparison of two $C_{3}$ and two $C_{4}$ grass species. Plant Physiol. 1983;71:789-96. https://doi.org/10.1104/pp.71.4.789.

Oren R, Sperry JS, Katul GG, et al. Survey and synthesis of intra- and interspecific variation in stomatal sensitivity to vapour pressure deficit. Plant, Cell Environ. 1999;22:1515-26. https://doi.org/10.1046/j.1365-3040.1999. 00513.x.

Pettigrew WT, Hesketh JD, Peters DB, et al. A vapor pressure deficit effect on crop canopy photosynthesis. Photosynth Res. 1990;24:27-34. 
Rawson HM, Begg JE, Woodward RG. The effect of atmospheric humidity on photosynthesis, transpiration and water use efficiency of leaves of several plant species. Planta. 1977;134:5-10.

Shekoofa A, Safikhan S, Snider JL, et al. Variation in stomatal conductance responses of cotton cultivars to high vapour pressure deficit under controlled and rainfed environments. J Agron Crop Sci. 2021;207:332-43. https://doi.org/10.1111/jac.12440,

Sherwood S, Fu Q. A drier future? Science. 2014;343:737-9. https://doi.org/10. 1126/science.1247620.

Slatyer RO, Bierhuizen JF. Transpiration from cotton leaves under range of environmental conditions in relation to internal and external diffusive resistances. Aust J Biol Sci. 1964;17:115-30.

Tennakoon SB, Hulugalle NR. Impact of crop rotation and minimum tillage on water use efficiency of irrigated cotton in a Vertisol. Irrig Sci. 2006;25:4552. https://doi.org/10.1007/s00271-006-0033-0.
Tennakoon SB, Milroy SP. Crop water use and water use efficiency on irrigated cotton farms in Australia. Agric Water Manag. 2003;61:179-94. https://doi. org/10.1016/s0378-3774(03)00023-4.

Ward WT, McTainsh G, McGarry D, et al. The soils of the Agricultural Research Station at 'Myall Vale', near Narrabri, NSW, with data analysis by fuzzy k-means. CSIRO Land and Water, Technical Report 21/99, July 1999, CSIRO, Australia; 1999

Yong JWH, Wong SC, Farquhar GD. Stomatal responses to changes in vapour pressure difference between leaf and air. Plant Cell Environ. 1997;20:1213-6. https://doi.org/10.1046/j.1365-3040.1997.d01-27.x.
Ready to submit your research? Choose BMC and benefit from:

- fast, convenient online submission

- thorough peer review by experienced researchers in your field

- rapid publication on acceptance

- support for research data, including large and complex data types

- gold Open Access which fosters wider collaboration and increased citations

- maximum visibility for your research: over 100M website views per year

At BMC, research is always in progress.

Learn more biomedcentral.com/submissions 